\title{
Surgery in the Management of Small Cell Lung Cancer
}

\author{
Robert J. Downey, MD,* and Lee M. Krug, MD, $†$ New York, New York
}

Key Words

Small cell lung cancer, surgery, metastases, thoracic surgery, pulmonary carcinoma

\section{Abstract}

Because most patients with small cell cancer of the lung present with distant metastatic disease, the treatment is almost always medical therapies without surgery. However, a small number of patients present with resectable disease, and this review summarizes the available literature addressing the possible role for surgery in the treatment of these patients. (JNCCN 2004;2:159-162)

$\mathbf{R}$ esection with curative intent is rarely possible in patients with small cell lung cancer (SCLC), because most patients present with either diffuse locoregional disease or distant metastases. Chemotherapy, which is well known to induce dramatic responses, is the mainstay of treatment for this disease. The addition of thoracic radiation therapy can improve local control and survival over chemotherapy alone for patients with limited stage disease. However, it is possible that (rarely) surgery may benefit SCLC patients. This review discusses the relevant literature on this subject. We must emphasize that clinical trials exploring the role of surgery in SCLC are difficult to conduct because of the rarity of resectable disease. As a result, the evidence available is often both based on small groups of patients and retrospective, and therefore, any advantage attributed to surgery in these studies must be considered unproven. Multiple comprehensive reviews on this topic are available for the reader desiring additional details or viewpoints. ${ }^{1-5}$

From the *Division of Thoracic Surgery, Department of Surgery, and tDivision of Thoracic Oncology, Department of Medicine, Memorial Sloan-Kettering Cancer Center, New York, New York.

Received on November 11, 2003; accepted for publication December 12, 2003.

No benefits or funds were received in support of this study. Correspondence: Robert Downey, MD, Division of Thoracic Surgery, Memorial Sloan-Kettering Cancer Center, 1275 York Avenue, New York, New York 10021. E-mail: downeyr@mskcc.org

\section{Review of the Literature}

The preferred treatment for SCLC before 1973 was surgical excision. However, a review from Memorial SloanKettering Cancer Center at that time suggested that only a fraction $(7 \%)$ of patients presented with resectable disease, and prolonged survival was rare. ${ }^{6}$ In a similar series from M. D. Anderson Cancer Center, ${ }^{7}$ the median survival of SCLC patients without known metastases was 5 months when treated surgically, and the longest survivor lived 39 months. These results were no better than those achieved historically by medical therapy alone. In a 1973 report summarizing the 10-year results of a British Medical Research Council (BMRC) study that randomized patients to receive either surgery alone $(n=71)$ or radiation therapy alone $(n=73)$, the authors found that "... radical radiotherapy has a somewhat better result than surgery in patients with SCLC." " This study has been criticized by some ${ }^{9}$ as being limited in that (1) disease had to be central (i.e., could be biopsied with a rigid bronchoscope), (2) no intraoperative staging was performed, and (3) only about half of the patients underwent complete resections. The study can be further faulted for not using modern imaging for staging. However, this study changed clinical practice in that resections were largely abandoned in favor of radiation therapy. Soon thereafter, effective chemotherapy was incorporated into the management of SCLC.

Since then, only a few studies have described patients with SCLC treated with surgery alone. ${ }^{10-12}$ One of these studies ${ }^{12}$ compared patients managed with surgery alone with those who received chemotherapy after resection, and the results are instructive. Stage I patients treated with surgery alone had a 5 -year survival of $12 \%$, but patients treated with surgery and postoperative chemotherapy had a 5 -year survival rate of $61 \%$. Given the limitations of the BMRC study, the subsequently published studies hold open the possibility that surgery may benefit a small group of patients. 
Two large studies address surgery with adjuvant chemotherapy. The first, from the University of Toronto, ${ }^{13}$ retrospectively described 77 patients with early stage SCLC treated initially by resection. Sixtythree patients subsequently received combination chemotherapy, 49 prophylactic cranial irradiation, and 35 received thoracic radiation. The overall 5-year survival was $31 \%$, but this was strongly associated with stage. Stage I patients had a 5 -year survival of $48 \%$; stage II, 25\%; and stage III, 24\%. A later article from the same group suggested that surgery followed by chemotherapy had the same outcome as treatment in the reverse order. ${ }^{14}$

The second study of adjuvant therapy was a prospective trial by The Lung Cancer Study Group of the International Society of Chemotherapy, which enrolled 183 patients with stage I (T1-2, NO) SCLC. ${ }^{15}$ After surgery, patients were randomized to receive standard chemotherapy with cyclophosphamide, doxorubicin, and vincristine, or sequential therapy with 3 different chemotherapy regimens. Thoracic radiation was not used, although patients with no evidence of disease were offered prophylactic cranial irradiation. The 30-month survival for N0 patients was $63 \%$ and for N2 patients was 37\%.

Several small retrospective and nonrandomized prospective studies showed the feasibility of treating patients with limited stage SCLC with induction therapy followed by surgery. ${ }^{16-19}$ As with the studies of surgery and adjuvant therapy, survival strongly corresponds with stage. In particular, patients with residual mediastinal disease fare poorly, suggesting a role for pre-resection mediastinoscopy. ${ }^{20}$

Although the benefit of combined chemoradiation for limited stage SCLC has been firmly established, a meta-analysis evaluating the role of thoracic radiotherapy ${ }^{21}$ found the local recurrence rate to be $35 \%$ to $50 \%$, which is where it has remained even with intensified radiation fractionation. ${ }^{22}$ This local failure rate has led to intermittent reconsideration of surgery as a better means of obtaining local control.

The only available prospective randomized study that addresses the relative effectiveness of surgery and radiation therapy was performed through the Lung Cancer Study Group. ${ }^{23}$ In that study, 328 patients with node-positive SCLC were enrolled; 146 responding patients were randomized to either surgery followed by thoracic radiation or radiation alone. Local failure rates and survival in the two groups were similar. However, this trial can be criticized for not using cisplatin-based chemotherapy or concurrent thoracic radiotherapy, limiting the applicability of its conclusion to current theory, and for only $50 \%$ of the patients being randomized.

The relative advantages of surgery versus radiation for local control in patients with N0-N1 and in patients with N2 disease after induction chemotherapy are not clearly known. Several small retrospective and nonrandomized prospective studies have evaluated patients with stage I-IIIA disease treated with induction therapy and surgery. The most recent of these studies enrolled 22 patients, of which 21 responding patients underwent resection. The authors found a 3-year survival rate of $73 \%$ for $\mathrm{NO}$ and $\mathrm{N} 1$ patients and $43 \%$ for N2 patients. ${ }^{19}$ Retrospective data on SCLC treated with induction chemotherapy and surgery suggest that patients with mediastinal nodal disease fare worse if treated with surgery rather than radiation. ${ }^{20}$

Finally, another rationale supporting surgery after initial therapy is for tumors of mixed histology. The diagnosis of mixed SCLC-NSCLC is rare, occurring in approximately $1 \%$ of patients with newly diagnosed SCLC. ${ }^{24}$ The NSCLC component may represent the residual tissue after the more chemosensitive SCLC has been eradicated. Of 28 specimens resected after chemotherapy in a University of Toronto series, ${ }^{25} 18$ had pure SCLC, 6 had pure NSCLC histology, and 4 were mixed in histology. In the Lung Cancer Study Group randomized trial of adjuvant surgery, ${ }^{15}$ NSCLC or mixed SCLC and NSCLC represented $11 \%$ of the resected specimens. In the largest series available, ${ }^{26}$ which describes 26 patients with mixed SCLCNSCLC, the 5-year survival for patients with stage I disease was $31 \%$, but for all other patients, it was $0 \%$.

\section{Practice Guidelines}

Given the data reviewed, we suggest the following guidelines for surgery in patients with SCLC:

\section{Solitary Pulmonary Nodules Identified Intraoperatively as SCLC}

If during thoracotomy for an indeterminate pulmonary nodule, the diagnosis of small cell carcinoma is made, a mediastinal lymph node dissection should be performed with frozen section analysis of the nodes. If limited disease that can be encompassed surgically by a lobectomy or bilobectomy is found, resection is reasonable. Because pneumonectomy is associated with a significant surgical mortality and limits the reserve 
of a patient who faces chemoradiotherapy, it will be only rarely appropriate.

Because presentation with resectable disease is common for histologies other than SCLC and uncommon for SCLC (occurring in only about 4\% of SCLC patients ${ }^{27}$ ), this allows pathologic confirmation that the disease is actually SCLC and not another entity such as a carcinoid. Furthermore, it allows complete staging, which will have prognostic and treatment implications. Finally, it is possible that resection of SCLC may be associated with a better rate of locoregional control.

In general, our practice is to recommend postoperative chemotherapy for resected NO small cell patients and postoperative chemoradiotherapy for patients with resected $\mathrm{N} 1$ or N2 disease. However, this is based on very little data.

\section{Very Early Stage SCLC Recognized Preoperatively}

Tumors diagnosed preoperatively as small cell carcinoma and that are clinically $\mathrm{NO}, \mathrm{MO}$ after a complete staging evaluation (including mediastinoscopy and possibly mediastinotomy) may be considered for surgical resection. Resection may reveal that the tumor is actually a carcinoid. Interoperative frozen section analysis of a complete hilar and mediastinal lymph node dissection is valuable; the presence of extensive nodal disease that would be difficult to encompass surgically would lead to consideration of aborting the resection. Postoperative chemotherapy is recommended for resected $\mathrm{NO}$ small cell patients, and postoperative chemoradiotherapy is recommended for resected N1 or N2 patients (again, based on limited data).

Tumors diagnosed preoperatively as small cell carcinoma and that are clinically $\mathrm{N} 1, \mathrm{M} 0$ after a complete staging evaluation (including mediastinoscopy and possibly mediastinotomy) are generally treated initially with chemotherapy and radiation, and if restaging is negative for distant metastatic disease, considered for resection.

Tumors diagnosed preoperatively as small cell carcinoma and that are pathologically proven to be N2 by mediastinoscopy or mediastinotomy are generally treated with definitive chemoradiation therapy.

\section{Growth in a Treated SCLC}

Growth in a residual mass of medically treated SCLC may be considered for resection in that about $10 \%$ of such patients will have residual non-small cell carci- noma that will not be responsive to small cell chemotherapy or may have a carcinoid misdiagnosed as SCLC. ${ }^{16,23,25}$

\section{New Mass After Treatment for SCLC}

A mass arising in a separate area of the lung more than 2 years after treatment for SCLC should be evaluated for possibly being a second primary cancer, which is one of the common causes of death in survivors of SCLC. ${ }^{28,29}$ If confirmed as a new primary, treatment should be according to standard principles for the management of lung cancer.

\section{References}

1. Shepherd FA. Surgical management of small cell lung cancer. In: Pass HI, Mitchell JB, Johnson DH, eds. Lung Cancer: Principles and Practice. Philadelphia, PA: Lippincott Williams and Wilkins, 2000.

2. Passlick B. Can surgery improve local control in small cell lung cancer? Lung Cancer 2001;33(Suppl1):S147-S151.

3. Kohman LJ. Is there a place for surgery in central small cell lung cancer? Chest Surg Clin N Am 1997;7:105-112.

4. Lassen U, Hansen HH. Surgery in limited stage small cell lung cancer. Cancer Treat Rev 1999;25:67-72.

5. Szczesny TJ, Szczesna A, Shepherd FA, et al. Surgical treatment of small cell lung cancer. Semin Oncol 2003;30: 47-56.

6. Martini N, Wittes RE, Hilaris BS, et al. Oat cell carcinoma of the lung. Clin Bull 1975;5:144-148.

7. Mountain CF. Clinical biology of small cell carcinoma: relationship to surgical therapy. Semin Oncol 1978;5:272-279.

8. Fox W, Scadding JG. Medical Research Council comparative trial of surgery and radiotherapy for primary treatment of small-celled or oat-celled carcinoma of the bronchus: Tenyear follow-up. Lancet 1973;2:63-65.

9. Deslauriers J. Surgery for small cell lung cancer. [Review] Lung Cancer 1997;17(Suppl1):S91-S98.

10. Prasad US, Naylor AR, Walker WS, et al. Long-term survival after pulmonary resection for small cell carcinoma of the lung [comment]. Thorax 1989; 44:784-787.

11. Shah SS, Thompson J, Goldstraw P. Results of operation without adjuvant therapy in the treatment of small cell lung cancer. Ann Thorac Surg 1992;54:498-501.

12. Coolen L, Van den Eeckhout A, Deneffe G, et al. Surgical treatment of small cell lung cancer. Eur J Cardio-Thorac Surg 1995;9:59-64.

13. Shepherd FA, Evans WK, FeldR, et al. Adjuvant chemotherapy following surgical resection for small-cell carcinoma of the lung. J Clin Oncol 1988;6:832-838.

14. Shepherd FA, Ginsberg RJ, Feld R, et al. Surgical treatment for limited small-cell lung cancer. The University of Toronto Lung Oncology Group Experience. J Thor Cardiovasc Surg 1991;101:385-393. 
15. Karrer K, UlspergerE. Surgery for cure followed by chemotherapy in small cell carcinoma of the lung. For the ISC-Lung Cancer Study Group. Acta Oncol 1995;34:899-906.

16. Prager RL, Foster JM, Hainesworth JD, et al. The feasibility of adjuvant surgery in limited-stage small cell carcinoma: A prospectiveevaluation. Ann Thorac Surg 1984;38:622-626.

17. Shepherd FA, Ginsberg RJ, Patterson GA, et al. A prospective study of adjuvant surgical resection after chemotherapy for limited small cell lung cancer. A University of Toronto Lung Oncology Group study. J Thor Cardiovasc Surg 1989;97:177-186.

18. Zatopek NK, Holoye PY, Ellerbroek NA, et al. Resectability of small-cell lung cancer following induction chemotherapy in patients with limited disease (stage II-IIIb). Am J Clin Oncol 1991;14:427-432.

19. Fujimori K, Yokoyama A, Kurita Y, et al. A pilot phase 2 study of surgical treatment after induction chemotherapy for resectable stage I to IIIA small cell lung cancer. Chest 1997;111:1089-1093.

20. Inoue M, Nakagawa K, Fujiwara K, et al. Results of preoperative mediastinoscopy for small cell lung cancer. Ann Thorac Surg 2000;70:1620-1623.

21. Pignon JP, Arriagada R, Ihde DC, et al. A meta-analysis of thoracic radiotherapy for small-cell lung cancer [comment]. N Engl J Med 1992;327:1618-1624.

22. Turrisi AT 3rd, Kim K, Blum R, et al. Twice-daily compared with once-daily thoracic radiotherapy in limited small-cell lung cancer treated concurrently with cisplatin and etoposide [comment]. N Engl J Med 1999;340:265-271.

23. Lad T, Piantadosi S, Thomas $P$, et al. A prospective randomized trial to determine the benefit of surgical resection of residual disease following response of small cell lung cancer to combination chemotherapy. Chest 1994;106(Suppl 6):320S-323S.

24. Hirsch FR, Matthews MJ, Aisner S, et al. Histopathologic classification of small cell lung cancer. Changing concepts and terminology. Cancer 1988;62:973-977.

25. Shepherd FA, Ginsberg R, Patterson GA, et al. Is there ever a role for salvage operations in limited small-cell lung cancer? [comment]. J Thor Cardiovasc Surg 1991;101:196-200.

26. Hage R, Elbers JR, Brutel de la Riviere A, et al. Surgery for combined type small cell lung carcinoma. Thorax 1998; 53:450-453.

27. Quoix E, Fraser R, Wolkove N, et al. Small cell lung cancer presenting as a solitary pulmonary nodule. Cancer 1990; 66:577-582.

28. Lassen $U$, Osterlind $K$, Hansen $M$, et al. Long-term survival in small-cell lung cancer: post-treatment characteristicsin patients surviving 5 to $18+$ years: an analysis of 1,714 consecutive patients. J Clin Oncol 1995;13:1215-1220.

29. Johnson BE, Linnoila RI, Williams JP, et al. Risk of second aerodigestive cancers increases in patients who survive free of small-cell lung cancer for more than 2 years. J Clin Oncol 1995;13:101-111. 